\title{
Study on the Effect of Air Circulator on Temperature Distribution in an Oyster Mushroom Farm
}

\author{
Won Geun Jeong ${ }^{1}$, Hack Kyu $\mathrm{Lim}^{2}$, Tae Han $\mathrm{Kim}^{3} *$ \\ ${ }^{1}$ Gimcheon Agricultural and Technical High School, Gyeongbuk, Korea \\ ${ }^{2}$ Division of Automotive, Industrial and Mechanical Engineering, Daegu University, Kyeongbuk, Korea \\ ${ }^{3}$ Dept. of Bio-industrial Machinery Engineering, Kyungpook National University, Daegu, Korea
}

Received: March 22 $2^{\text {th }}, 2013$; Revised: May 14 ${ }^{\text {th }}, 2013$; Accepted: May 31 ${ }^{\text {th }}, 2013$

\section{Abstract}

Purpose: Recently, domestic and abroad consumption of mushroom has been increasing. Especially, oyster mushroom has been the most consumed product, sharing one third of the mushroom market. The air temperature differences between relative positions of the mushroom farms were needs to be minimal. However, in reality, the air temperature differences ranged from 2 to $5^{\circ} \mathrm{C}$. Because of this, the mushrooms are non-uniform growth as well as decrease in both quality and quantity. Although air circulators have been employed by oyster mushroom farms to minimize air temperature differences, no experiments have been performed to illustrate the effect of the air circulators. Methods: This experiment is designed to analyze the effect of the air circulation by constructing a prototype air circulator and measuring the air temperature when the circulator was position at different heights $(50 \mathrm{~cm}, 150 \mathrm{~cm}, 200 \mathrm{~cm})$ from the floor in the center. Result: The horizontal plane air temperature of the first growing bed when the air circulator was installed $50 \mathrm{~cm}$ above the floor in the center, once not using the air circulators and the other time using the air circulators, yielded the air temperature differences of $8.6^{\circ} \mathrm{C}$ and $1.8^{\circ} \mathrm{C}$ and deviations of 2.82 and 0.60 , respectively. The third growing bed's air temperature differences were $10.0^{\circ} \mathrm{C}, 1.6^{\circ} \mathrm{C}$ and deviations 3.28, 0.64, each respectively. These outcomes proved that the use of air circulators minimized the air temperature difference and deviation. The use of air circulators helped minimize the air temperature differences and the derivations in oyster mushroom farm. Conclusion: The use of air circulators helped balance the air temperature distribution in oyster mushroom farm

Keywords: Air temperature distribution, Air circulator. Oyster mushroom farm, Effect of air circulation

\section{Introduction}

Korea's number of mushroom farms amounts to 4,160. The total cultivating area is approximately $764 \mathrm{ha}$, and the production is $173,580 \mathrm{M} / \mathrm{T}$. This includes 2,200 oyster mushroom farms, which occupy $30 \%$ of all cultivating area. The quantity of oyster mushroom production is $45,200 \mathrm{M} / \mathrm{T}$, which occupies $26 \%$ of the total production of mushroom ; thus, oyster mushroom is undoubtedly a significant contributor to the farm income (Ministry for

\footnotetext{
*Corresponding author: Tae Han Kim

Tel: +82-53-950-5793; Fax: +82-53-950-6780

E-mail: thakim@knu.ac.kr
}

Food, Agriculture, Forestry and Fisheries, 2010). A successful mushroom production necessitates the appropriate air temperature, humidity, and ventilation. Regularly, thermal death point of oyster mushrooms' fungus is below -30C, and its high air temperature is $40^{\circ} \mathrm{C}$ and above. Its air temperature range for survival is between 5 to $\sim 32^{\circ} \mathrm{C}$, and the optimum growth air temperature is $27^{\circ} \mathrm{C}$. However, when culture fungus, air temperatures below $15^{\circ} \mathrm{C}$ or above $30^{\circ} \mathrm{C}$ will prove unfit for or delay its growth. Air temperatures between 22 and $24^{\circ} \mathrm{C}$ are maintained for mushroom cultivation; consequently, the optimum air temperature for culture fungus becomes $27^{\circ} \mathrm{C}$, due to the respiration process of the fungus (Rural 
Development Administration, 1998 ; Hong et al., 1992 ;Hong, 1978). The oyster mushroom farm is constructed to accommodate two sides of four growing beds, in total 8 growing beds, and the air temperature differences between relative positions of the mushroom farms were needs to be minimal. However, in reality, the air temperature differences ranged from 2 to $5^{\circ} \mathrm{C}$ (Yoon et al. 2004). Because of this, the mushrooms are non-uniform growth as well as decrease in both quality and quantity. To alleviate this challenge, farms have adopted and employed air circulators(Kim, 2005), but no experiments clearly illustrate the effect of air circulation. This experiment investigated the effect of air circulator on reducing the difference between the highest and the lowest air temperature in an oyster mushroom farm.

\section{Materials and Methods}

\section{Design of experimental equipment}

The air circulator was designed with two suction ports and one discharge port it to achieve a more even air temperature distribution in the interior of oyster mushroom farms. The air circulator used in this experiment had the size of $1,180 \times 550 \times 830 \mathrm{~mm}$ (illustrated in table 1 and figure 1). The suction port have a diameter of $\varphi 260$

Table 1. Specification of air circulator

\begin{tabular}{|c|c|c|}
\hline \multicolumn{2}{|c|}{ Size $(W \times L \times H)(m m)$} & $1,180 \times 550 \times 830$ \\
\hline \multicolumn{2}{|c|}{ Suction Port (mm) } & $\varphi 260$ \\
\hline \multicolumn{2}{|c|}{ Discharge port (mm) } & 甲 320 \\
\hline \multirow{2}{*}{ Fan } & Suction Port (mm) & 甲 $240\left(1,200 \mathrm{~m}^{3} / \mathrm{hr}\right)$ \\
\hline & Discharge port (mm) & $\varphi 300\left(1,800 \mathrm{~m}^{3} / \mathrm{hr}\right)$ \\
\hline
\end{tabular}

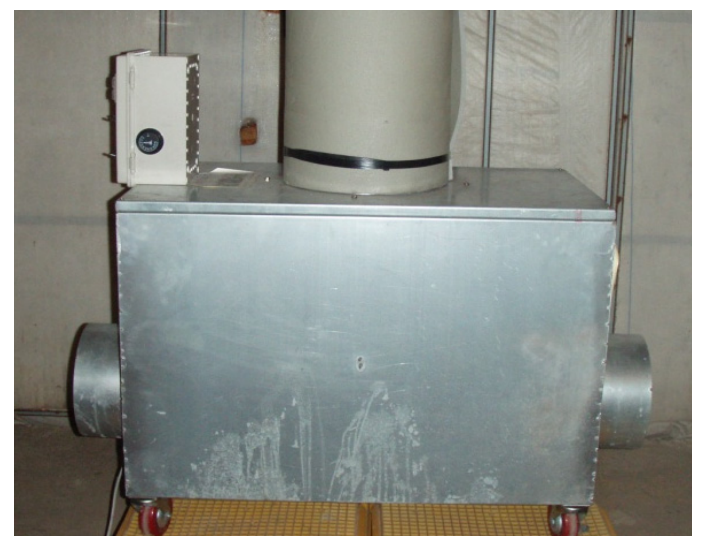

Figure 1. Picture of air circulator. $\mathrm{mm}$, and the discharge port a diameter of $\varphi 320 \mathrm{~mm}$. Fans used for the inlets had a diameter of $\varphi 240 \mathrm{~mm}$, and the fan used for the outlet.

a diameter of $\varphi 300 \mathrm{~mm}$. Because one mushroom farm's size is $20 \times 5.5 \times 4.0 \mathrm{~m}$ and has an interior volume of $440 \mathrm{~m}^{3}$, that the capacity of the air circulator should be approximately $1,000 \mathrm{~m}^{3} / \mathrm{hr}$ was determined.

\section{Experimental method}

Figure 2 demonstrates the setting points of air temperatures sensors for each location of the growing beds. As shown below, the horizontal plane of the bed was divided in five, and the eight sensors were installed 10 $\mathrm{mm}$ above the surface of culture mediums per each growing bed, in total at 32 disparate locations. The air temperature was measured using the sensors of $\mathrm{K}$ type thermocouples and multi-thermometers (RM-2500, Okura, Japan). The air temperatures of the growing beds were measured 90 minutes after heating the farm and using air circulators, which would have stabilized the internal air

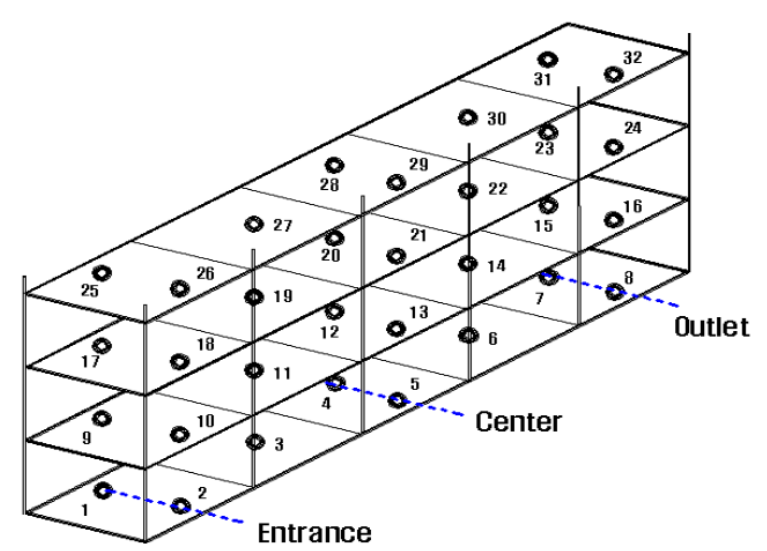

Figure 2. Setting point of air temperature sensor.

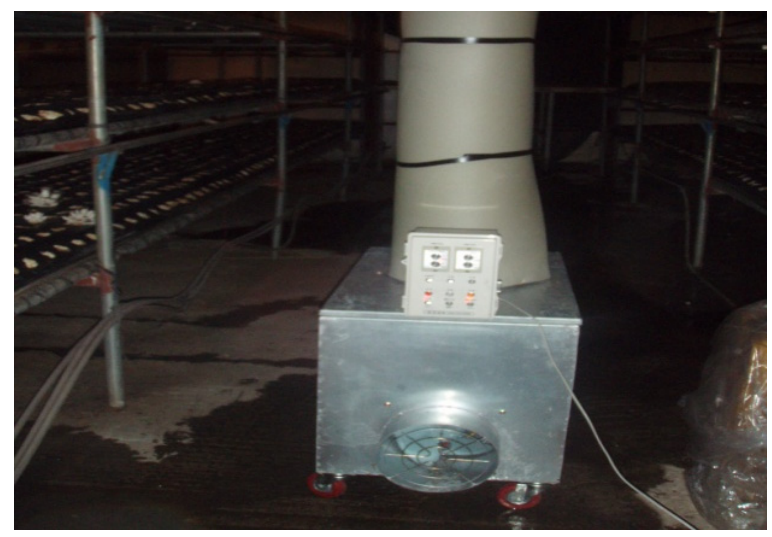

Figure 3. Air circulation unit setting in the oyster mushroom farm. 
temperature of the oyster mushroom farm by that point in time.

The air circulators were installed at the center of the growing beds, which are the numbers 4 and 5 in Figure1. The center is 9.0 meters from each end of the bed. To accurately illustrate the effect of the air circulators, the air temperature was once measured without the use of air circulators and the other time with the use of air circulators, air circulators being the independent variable in this case. Figure 3 shows the installation of the air circulators. Furthermore, the heater was positioned at either the left or the right corner of the entrance, modeled exactly after any mushroom farm.

\section{Results and Discussion}

Figure 4 depicts the air temperature distribution of the horizontal plane of the first growing bed when the air circulator was installed $50 \mathrm{~cm}$ above the floor in the center. Figure (a) shows the results when the air circulators were not used. The lowest air temperature was $12.1^{\circ} \mathrm{C}$, and the highest air temperature $20.7^{\circ} \mathrm{C}$; the air temperature difference was $8.6^{\circ} \mathrm{C}$, and deviation being 2.82 . Figure (b) shows the results when the air circulators were used. The lowest air temperature was $14.4^{\circ} \mathrm{C}$, and the highest air temperature $16.2^{\circ} \mathrm{C}$; the air temperature difference was $1.8^{\circ} \mathrm{C}$, and deviation being 0.60 . Compared to the results of Figures (a) and (b), the use of air circulators helped even out the air temperature distribution by decreasing the air temperature difference.

Figure 5 shows the air temperature distribution of the horizontal plane of the third growing bed when the air circulator was installed $50 \mathrm{~cm}$ above the floor in the center. Figure (a) shows the results when the air circulators were not used. The lowest air temperature was

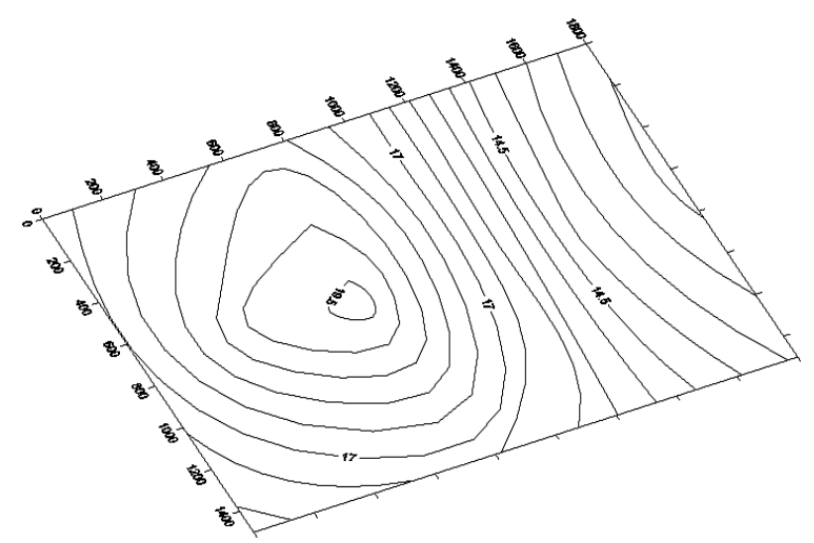

(a) non-air circulation

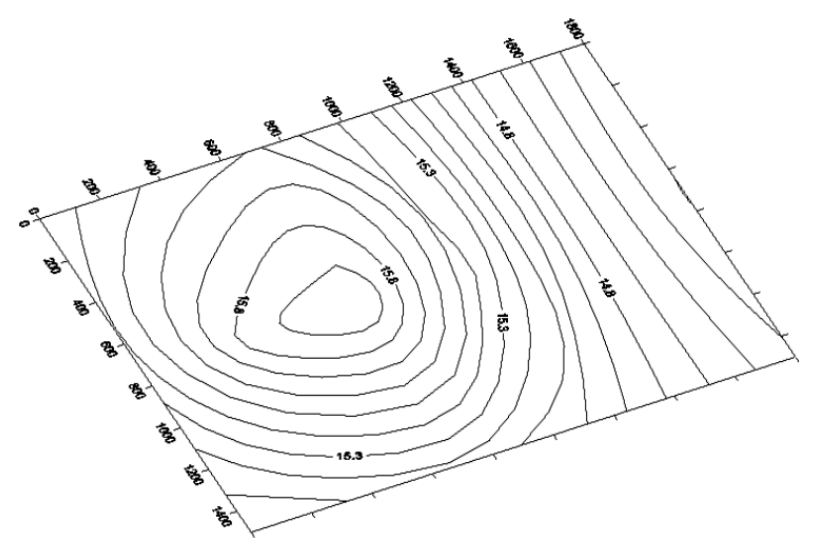

(b) air circulation center $50 \mathrm{~cm}$

Figure 4. Air temperature distribution of horizontal plane at 1 st bed with circulating.

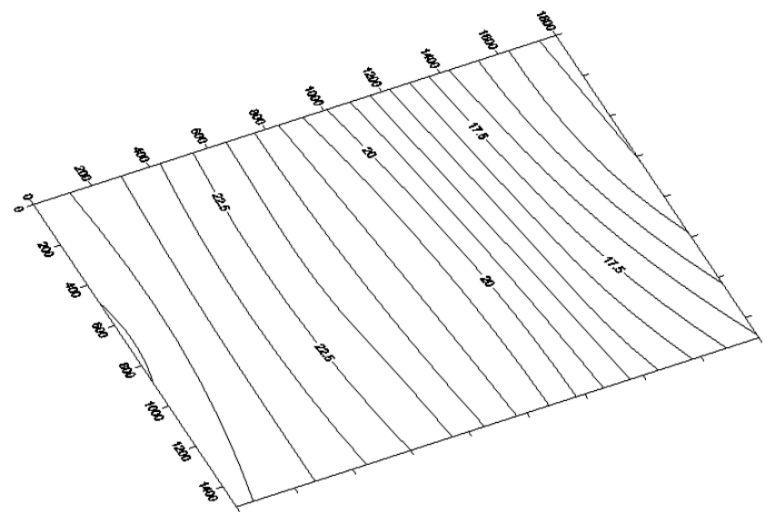

(a) non-air circulation

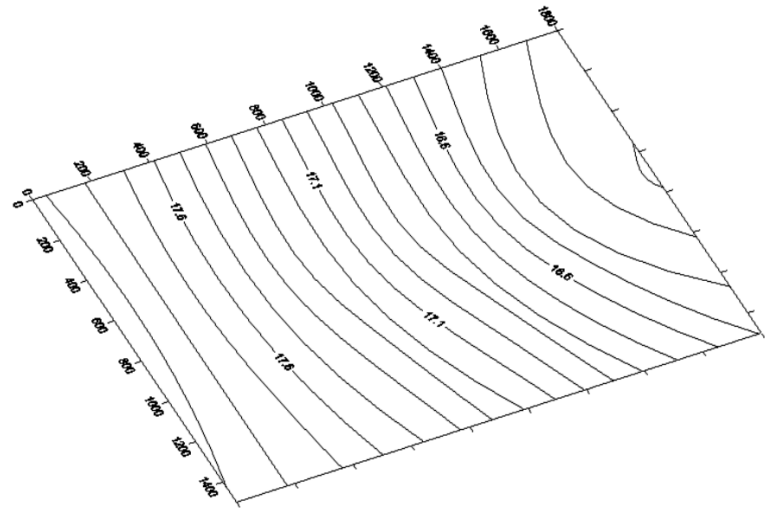

(b) air circulation center $50 \mathrm{~cm}$

Figure 5. Air temperature distribution of horizontal plane at 3rd bed with circulating. 
$14.8^{\circ} \mathrm{C}$, and the highest air temperature $24.8^{\circ} \mathrm{C}$; the air temperature difference was $10.0^{\circ} \mathrm{C}$, and deviation being 3.28. Figure (b) shows the results when the air circulators were used. The lowest air temperature was $16.3^{\circ} \mathrm{C}$, and the highest air temperature $17.9^{\circ} \mathrm{C}$; the air temperature difference was $1.6^{\circ} \mathrm{C}$, and deviation being 0.64 . Compared to the results of Figures (a) and (b) the use of air circulators helped even out the air temperature distribution by decreasing the air temperature difference.

Combining the results of Figures 4 and 5, using the air circulators helped increase the lowest air temperature and decrease the highest air temperature, thereby decreasing the overall air temperature difference. Therefore, the use of air circulators showed a more homogeneous air temperature distribution.
Figure 6 depicts the air temperature distribution of the vertical plane of the entrance. Figure (a) shows the results when the air circulators were not used. The lowest air temperature was $15.9^{\circ} \mathrm{C}$, and the highest air temperature $24.7^{\circ} \mathrm{C}$; the air temperature difference was $8.8^{\circ} \mathrm{C}$, and deviation being 3.67. Figure (b) shows the results when the air circulators were used. The lowest air temperature was $15.1{ }^{\circ} \mathrm{C}$, and the highest air temperature $18.0^{\circ} \mathrm{C}$; the air temperature difference was $2.9^{\circ} \mathrm{C}$, and deviation being 1.11. Compared to the results of Figures (a) and (b), the use of air circulators helped even out the air temperature distribution by decreasing the air temperature difference.

Figure 7 depicts the air temperature distribution of the vertical plane of the center. Figure (a) shows the results

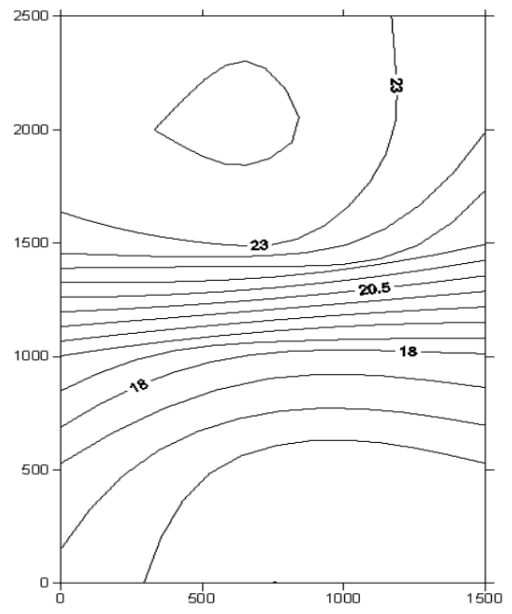

(a) non-air circulation

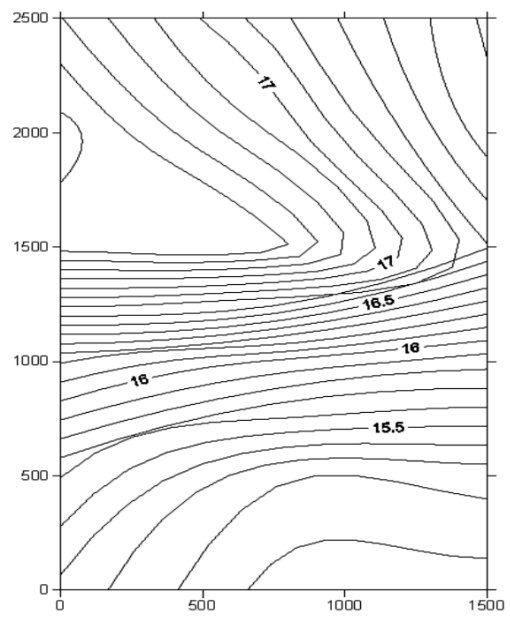

(b) air circulation center $50 \mathrm{~cm}$

Figure 6. Air temperature distribution of vertical plane at entrance with circulating.

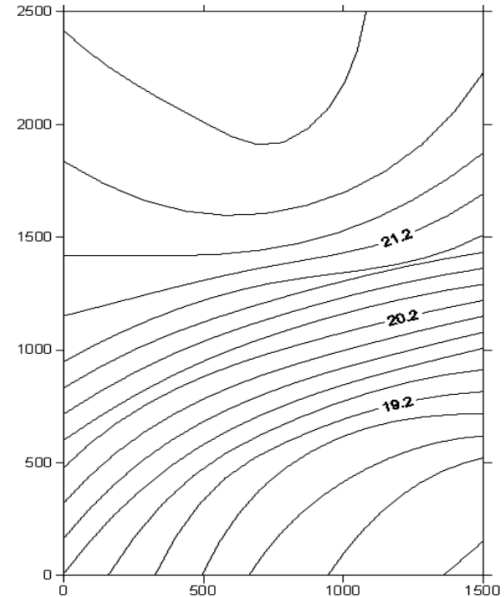

(a) non-air circulation

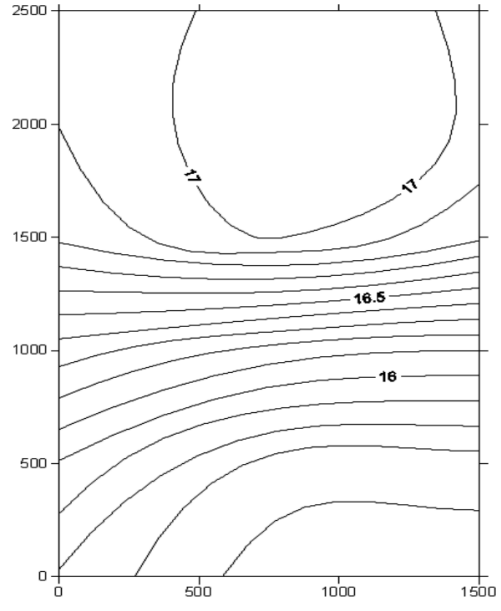

(b) air circulation center $50 \mathrm{~cm}$

Figure 7. Air temperature distribution of vertical plane at center with circulating. 


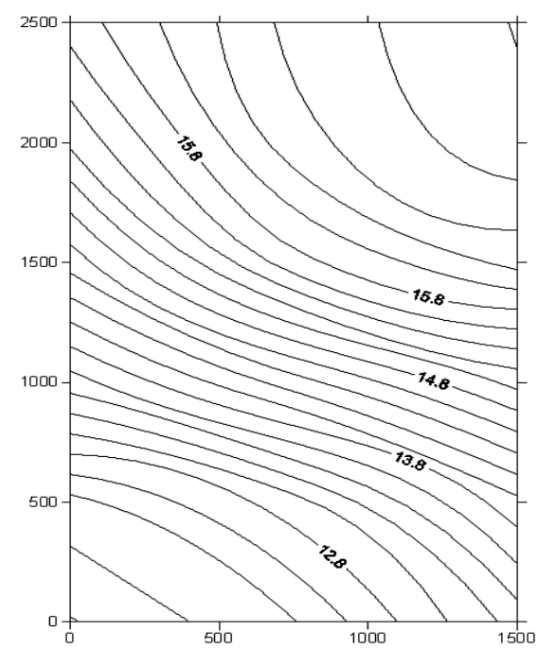

(a) non-air circulation

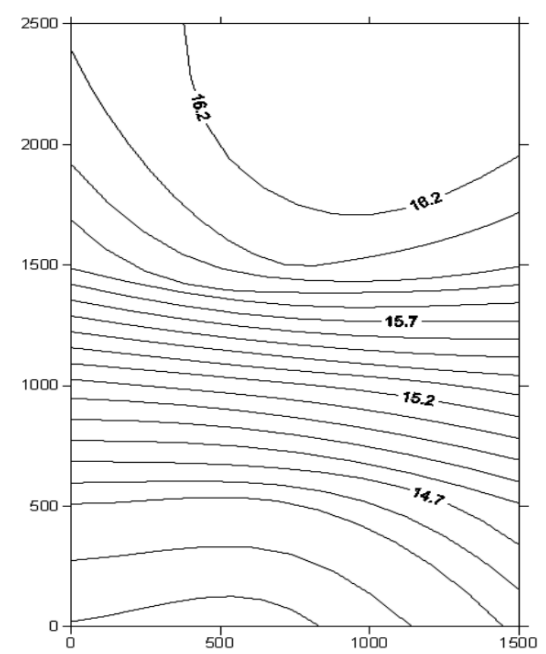

(b) air circulation center $50 \mathrm{~cm}$

Figure 8. Air temperature distribution of vertical plane at outlet with circulating.

when the air circulators were not used. The lowest air temperature was $18.2^{\circ} \mathrm{C}$, and the highest air temperature $22.0^{\circ} \mathrm{C}$; the air temperature difference was $3.8^{\circ} \mathrm{C}$, and deviation being 1.27. Figure (b) shows the results when the air circulators were used. The lowest air temperature was $15.5^{\circ} \mathrm{C}$, and the highest air temperature $17.4^{\circ} \mathrm{C}$; the air temperature difference was $1.9^{\circ} \mathrm{C}$, and deviation being 0.65 .

Figure 8 shows the air temperature distribution of the vertical plane of the exit. Figure (a) shows the results when the air circulators were not used. The lowest air temperature was $12.2^{\circ} \mathrm{C}$, and the highest air temperature $16.8^{\circ} \mathrm{C}$; the air temperature difference was $4.6^{\circ} \mathrm{C}$, and deviation being 1.52 . Figure (b) shows the results when the air circulators were used. The lowest air temperature was $14.4{ }^{\circ} \mathrm{C}$, and the highest air temperature $16.4{ }^{\circ} \mathrm{C}$; the air temperature difference was $2.0^{\circ} \mathrm{C}$, and deviation being 0.78. Combining the results of Figures 6, 7 and 8, using the air circulators decreased the lowest air temperature and the highest air temperature. On the other hand, on the exit side, the lowest air temperature increased a little and the highest air temperature remained about the same. Thus, the data show that the heaters, which were installed at the entrance side, affected even the air temperatures of the exit side through air circulation.

Even when the air circulator was installed $150 \mathrm{~cm}$ and $200 \mathrm{~cm}$ above the floor in the center, using the air circulators helped stabilize the air temperature differences and reach a more equal air temperature distribution.

\section{Conclusions}

This experiment is designed to analyze the effect of the air circulation by constructing a prototype air circulator and measuring the air temperature of various growing beds when the circulator was position at different heights $(50 \mathrm{~cm}, 150 \mathrm{~cm}, 200 \mathrm{~cm})$ from the floor in the center. The horizontal plane air temperature of the first growing bed when the air circulator was installed $50 \mathrm{~cm}$ above the floor in the center, once not using the air circulators and the other time using the air circulators, yielded the air temperature differences of $8.6^{\circ} \mathrm{C}$ and $1.8^{\circ} \mathrm{C}$ and deviations of 2.82 and 0.60 , respectively. The third growing bed's air temperature differences were $10.0^{\circ} \mathrm{C}, 1.6^{\circ} \mathrm{C}$ and deviations $3.28,0.64$, each respectively. These outcomes proved that the use of air circulators minimized the air temperature difference and deviation.

Likewise, the first time without the air circulators and the second time with the air circulators, the vertical plane of the entrance side had air temperature differences of $8.8^{\circ} \mathrm{C}, 2.9^{\circ} \mathrm{C}$ and deviations of $3.67,1.11$, each respectively. The center had air temperature differences of $3.8^{\circ} \mathrm{C}$, $1.9^{\circ} \mathrm{C}$ and deviations of $1.27,0.55$, each respectively. The exit side had air temperature differences of $4.6^{\circ} \mathrm{C}, 2.0^{\circ} \mathrm{C}$ and deviations of $1.52,0.78$, each respectively. These outcomes proved that the use of air circulators minimized the air temperature difference and deviation.

Even the installation of air circulators in the center at the heights of $150 \mathrm{~cm}$ and $200 \mathrm{~cm}$ from the floor did not alter the fact that the use of air circulators helped minimize 
the air temperature differences and the derivations. Thus, the use of air circulators helped balance the air temperature distribution.

\section{Conflict of Interest}

No potential conflict of interest relevant to this article was reported.

\section{Acknowledgement}

This research was supported by Kyungpook National University Research Fund. 2012

\section{References}

Hong, B. S., C. H. Song, S. Y. Hwang and H. C. Yang. 1992.
Development of Substrate and Cultural Method for the Cultivation of Pleurotus Sajor-caju 1992. Kor. J. Mycol. 20(4):354-359 (In Korean).

Hong, J. S. 1978. Studies on the Physio-chemical properties and the cultivation of oyster mushroom. Journal of the Korean Society for Applied Biological Chemistry 21(3):150-184 (In Korean).

Jeong, W. G. H. K. Lim and T. H. Kim. 2012. Analysis of Air Circulation in Oyster Mushroom Farm. Journal of Biosystems Engineering 37(2):75-81.

Kim, Y. J. 2005. Air Mixing device for Hothouse. Korean Intellectual Property Office (In Korean).

Ministry for Food, Agriculture, Forestry and Fisheries. 2010. Statics of Mushroom Productions (In Korean).

Rural Development Administration. 1998. Cultivation technology of mushroom. pp.32-33 (In Korean).

Yoon, Y. C., W. M. Suh and C. Yu. 2004. Analysis of Actual States of Facilities for Pleurotus eryngii Cultivation -Based on Western Gyeongnam Area. Journal of BioEnvironment Control 13(4):217-225 (In Korean). 